\title{
Organization and functioning of liberalized electricity markets: An overview of the Dutch market
}

\author{
Fehmi Tanrisever $^{\mathrm{a}}$, Kursad Derinkuyu ${ }^{\mathrm{b}, *, 1}$, Geert Jongen ${ }^{\mathrm{c}}$ \\ ${ }^{a}$ Faculty of Business Administration, Bilkent University, Ankara, Turkey \\ ${ }^{\mathrm{b}}$ Logistics Management Department, University of Turkish Aeronautical Association, Ankara, Turkey \\ c AlpInvest Partners B.V., Amsterdam, The Netherlands
}

\section{A R T I C L E I N F O}

Article history:

Received 10 November 2014

Received in revised form

19 March 2015

Accepted 7 July 2015

Available online 30 July 2015

Keywords:

Electricity markets

Futures exchange

Market organization

Electricity trading

\begin{abstract}
A B S T R A C T
In this paper, we examine the organization and the functioning of the Dutch electricity market. First we describe the organization of the Dutch electricity supply chain and the role of the main market participants including the transmission system operator, distribution system operators, program responsible parties and metering companies. We then describe the organization of financial trading and clearing mechanism of electricity through the organized futures exchange (The European Energy Derivatives Exchange), and the spot market (Amsterdam Power Exchange) which includes the day-ahead market and intra-day markets. We also detail the functioning of the imbalance market and reserve capacity management in the Netherlands.

Through a set of numerical analysis, we provide an exploratory analysis of the APX day-ahead spot prices and the real-time imbalance prices using electricity price data from 2002 to 2013. We observe the price spikes both in the day-ahead and imbalance markets usually occur around 6-10 AM and 5-7 PM. We also observe that in the imbalance market system overages happen significantly more often than shortages pointing out that the market tends to buy more than what is demanded. This could be explained by the risk attitude of the market participants in the imbalance market.
\end{abstract}

(c) 2015 Elsevier Ltd. All rights reserved.

\section{Contents}

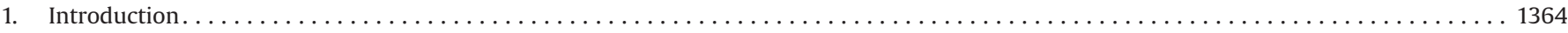

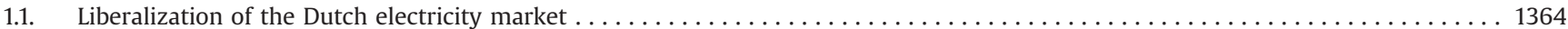

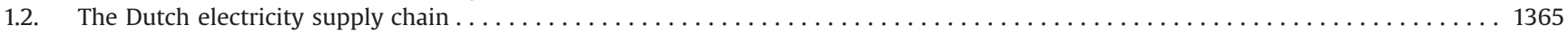

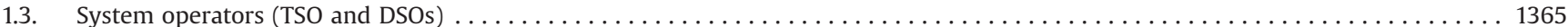

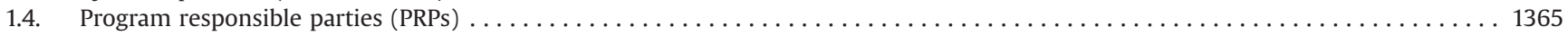

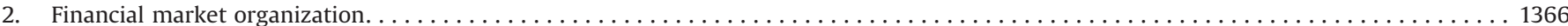

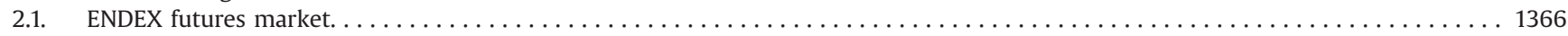

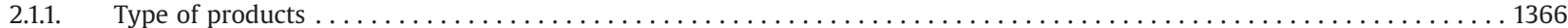

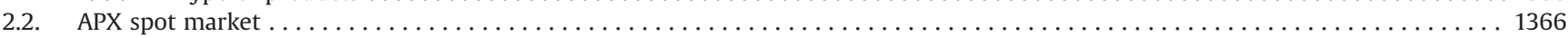

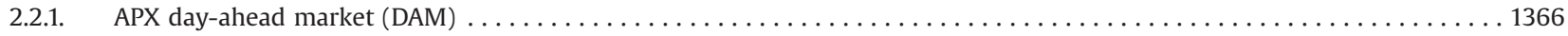

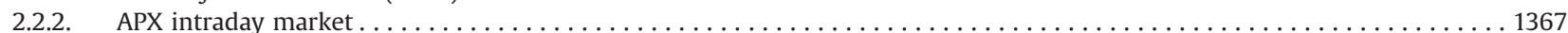

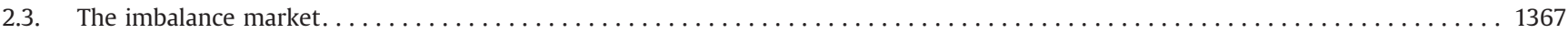

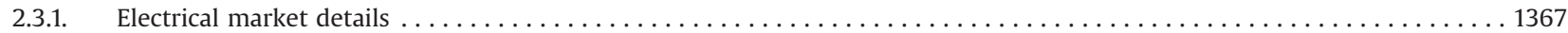

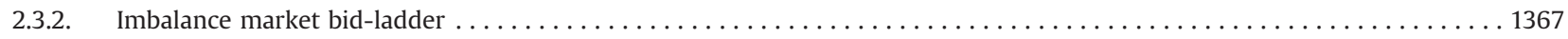

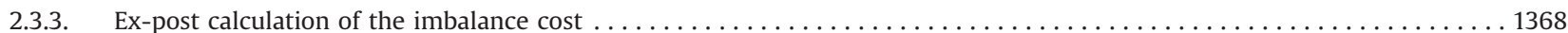

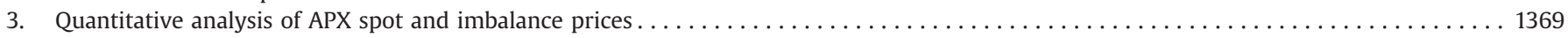

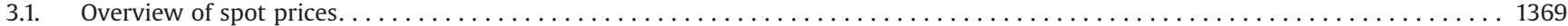

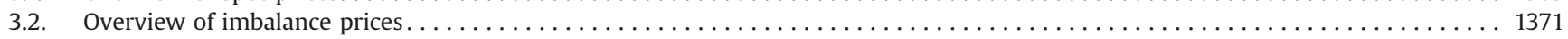

\footnotetext{
*Correspondence to: Türk Hava Kurumu Üniversitesi, Hayati Yazıcı Fakülteler Binası, Bahçekapı Mahallesi, Okul Sokak No. 11, Etimesgut, Ankara 06790, Turkey. Tel.: +90 3125896162; fax: +90 3123428460

E-mail addresses: tanrisever@bilkent.edu.tr (F. Tanrisever), kursad@utexas.edu (K. Derinkuyu), geertjongen@gmail.com (G. Jongen).

${ }^{1}$ Mail: Türk Hava Kurumu Üniversitesi, Hayati Yazıcı Fakülteler Binası, Bahçekapı Mahallesi, Okul Sokak No:11, Etimesgut / Ankara, 06790, Turkey
} 


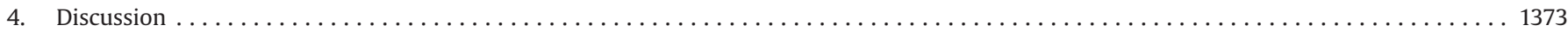

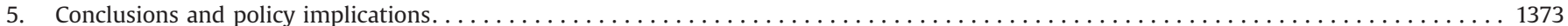

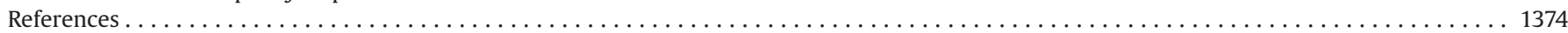

\section{Introduction}

Liberalization of the Dutch electricity market has started with the introduction of the 1998 Electricity Act. This act provided individual customers and suppliers with more freedom when procuring and selling electricity, while also establishing a market framework that is focused on reliability, sustainability and efficiency. The 1998 Electricity Act established a new state-owned entity, Tennet, to serve as the transmission system operator (TSO) of the high voltage grid $(220 \mathrm{kV}$ and $380 \mathrm{kV})$. Later, the Dutch government also unbundled the medium- and low-voltage transmission grids $(<110 \mathrm{kV})$ and generators in 2008 [7]. This resulted in a new group of entities, called distribution system operators (DSOs), which own and manage the medium- and low-voltage transmission grids.

Following the introduction of the Electricity Act of 1998, the Dutch electricity market has developed into a complex business environment in which market parties can freely trade electricity. The Dutch TSO, Tennet, is the main hub for all transactions and also the owner of the Amsterdam Power Exchange (APX), which trades and clears electricity contracts in the Day-Ahead Market. Tennet and APX are also the parties that enable cross-border transactions, either through auctioning of transmission capacity or through the Day-Ahead Market. The cross-border integration of electricity markets is currently in progress in Europe [29,2,14].

Transmission constraints in the Netherlands also play a key role in electricity markets, especially when considering cross-border transactions. In general, transmission constraints between different regions or countries may have a significant impact on price dynamics (Haldrup and Nielsen [15]), and amplify the volatility of prices. Transmission constraints can cause different prices in different regions and some of these regions can suffer from volatile prices. As demand increases and capacity utilization increases as well, more expensive plants have to be activated. This can cause the price curve to be very steep $[26,1]$.

In electricity markets, spot and futures contracts only function as a preliminary schedule since the demand and supply of electricity cannot be predicted perfectly; and hence another market is needed for ancillary services. The reserve capacity (imbalance) market is the marketplace where these services are traded. These services are provided by power plants and factories that are able to react to deviations in real-time from the preliminary schedule [36]. In particular, the capacity reserve market values the flexibility of electricity generation and consumption, while the spot markets only value the energy content of the transactions (Möller et al. [27]).

In this paper, we provide an overview of the functioning and organization of the Dutch electricity markets. First we elaborate on the liberalization of the markets followed by a discussion on electricity generation and distribution. The discussion focuses on the main market participants, such as the transmission system operator, distribution system operators, program responsible parties and retailers. Following that, we describe the organization of the financial trading and clearing mechanisms for electricity through the organized futures exchange, European Energy Derivatives Exchange (ENDEX), and the spot market, the Amsterdam Power Exchange, which includes the day-ahead and intra-day markets. Finally, we detail the functioning of the imbalance market and real-time reserve capacity management.
We also provide an exploratory analysis of the prices in these markets. We observe that price spikes both in the day-ahead and imbalance markets usually occur around 6-10 AM and 5-7 PM. Nevertheless, the imbalance prices are significantly more volatile than the day-ahead prices. In particular, although day-ahead market prices do not present any downward spikes below three standard deviations of the mean; the imbalance market does have such spikes. In addition, a close examination of the imbalance market reveals that the risk premium in the imbalance market for buying electricity (relative to day-ahead market) is $4.94 \mathrm{EUR} / \mathrm{MWh}$ while the premium for selling to the system is $4.79 \mathrm{EUR} / \mathrm{MWh}$. Unlike usual commodity and stock markets, the imbalance market displays different risk-premiums for buying and selling electricity. This is because $18 \%$ of the time the Dutch system operator executes both an upward dispatch and a downward dispatch during the same program time unit (PTU) which leads to diverging buying and selling prices for that time period.

\subsection{Liberalization of the Dutch electricity market}

In the European Union, liberalization and restructuring of electricity sector dominates the energy policies since the middle of the 1990s. The overarching aim of these policies is to design an efficient, competitive and sustainable energy market across the European Union. Three electricity related directives (European Commission: 1996/92; 2003/54 and 2009/72) are introduced for the liberalization of the electricity markets in Europe [23]. The first energy directive consisted of common rules for the reorganization of the national markets, whereas the second directive introduces the conditions for cross-border trading of electricity. It also orders to separate core activities of the network companies, such as the generation, trade and sale of energy. The third directive established the Agency for the Cooperation of Energy Regulators to help managing the cross-border trading of electricity.

One of the fundamental concepts of these directives is so called unbundling, the separation of the market functions traditionally provided by a single utility into functionally independent parts. The policy makers decide on the degree of unbundling. Four different types of unbundling can be distinguished: functional unbundling, management unbundling, legal unbundling and ownership unbundling $[17,3,10]$. The Dutch practice follows the ownership unbundling option, which is the splitting of commercial activities from network operations (this option is also favored by Soares and Sarmento [28] for electricity networks). In this model, generation companies cannot acquire shares in network operators and similarly, network operators cannot hold shares of generation companies. In parallel to the unbundling process, new regulations also introduced competition to the wholesale market through supplier selection. Starting with the large industrial consumers in 1998, the demand side of the market is fully liberalized by 2004 [6].

The Dutch TSO, Tennet, is the main hub for all transactions and is the participant through which the government enforces and steers the market. The distribution of electricity is handled by nine state-owned distribution system operators (DSOs). The main purpose of this setup is to isolate the natural monopolies from the rest of the electricity supply chain (including production and retailing) where the firms can freely compete. DSOs are regulated by the government, and they are compensated based on their 
relative performance in terms of quality (interruptions in service) and efficiency (distribution losses).

The directives of European Commission actually aim to establish a single European Energy Market. To support this objective, firstly ERGEG (European Regulators' Group for Electricity and Gas) was founded in 2003 and then ACER (Agency for the Cooperation of Energy Regulators) was established in 2011. The Netherlands also joined to these activities, and European Market Coupling Company (EMCC) was founded in 2008 to control the flow between regions under the principles of ITVC (Interim Tight Volume Coupling). To further extend the coupling, seven power exchanges (APX, Belpex, EPEX SPOT, GME, Nord Pool Spot, OMIE and OTE) has started the project called Price Coupling of Regions (PCR) in 2010. EMCC passed on its duty to its successor NorthWestern Europe (NWE) price coupling system (including countries Denmark, Finland, Norway, Sweden, Great Britain, Belgium, France, Germany, Luxemburg and the Netherlands) in February 2014. Finally, PCR project combined NWE and South-Western Europe (SWE) regions by using EUPHEMIA (Pan-European Hybrid Electricity Market Integration Algorithm) in May 2014 [25,24,9].

The impact of the liberalization efforts in the Netherlands, since the introduction of the Electricity Act of 1998, is mostly in line with the predictions of the classical economic theory. As predicted by the regulation theory $[30,28,20]$, ownership unbundling in the Netherlands seems to have served its purpose by creating competitive supply and wholesale markets. In this regard, ownership unbundling seems to have the biggest impact on the market. Streimikiene et al. [31] provide a comprehensive analysis and review on the impact of market liberalization on electricity prices in Europe. They find that the effect of liberalization on electricity prices is mixed on households and industrial consumers and depends on the country. In the Netherlands, our analysis shows that the spot prices as well as the volatility of the spot prices have decreased during the last 10 years. According to World Economic Forum the Netherlands ranked 26th among 125 countries in the global energy architecture index in 2015 [42].

\subsection{The Dutch electricity supply chain}

The Dutch electricity supply chain has restructured after the deregulation of the market in 1998. Today, the electricity supply chain consists of six independent parties including the generation, trading (program responsible parties), transmission, distribution, metering and supplier companies, as illustrated in Fig. 1. Below we describe the roles of system operators and program responsible parties (PRPs) in more detail.

\subsection{System operators (TSO and DSOs)}

Tennet is the backbone of the Dutch electricity market and the manager of the $110 \mathrm{kV}, 150 \mathrm{kV}, 220 \mathrm{kV}$ and $380 \mathrm{kV}$ grids. Its network connects all regional electricity grids with each other and with the European network. The company is a state-controlled monopoly.

Tennet requires market participants to provide two sets of information, a T-prognosis and an E-program, before the physical delivery of electricity. The T-prognosis is the forecasted flow of electricity used by Tennet to ensure grid stability. Tennet calculates the total expected electrical flows through the system, and if the flows violate one or more of the capacity constraints on the inter-grid connections, then it can block those requests for transportation capacity. The E-program is the net position of each participant in the market for each program time unit (PTU). All E-programs need to be ratified by Tennet to ensure that demand and supply of electricity is balanced on the grid. These programs are also used to calculate and settle imbalance payments after the physical delivery of electricity [34].

In addition, Tennet and the other European TSOs daily communicate the availability of transmission capacity. Currently, Tennet has high voltage connections with Germany, United Kingdom, Belgium and Norway [37]. The international connection capacity is auctioned through the Capacity Allocation Service Company (CASC) platform. Through this platform yearly, monthly and daily auctions are organized to allocate the cross-border transportation capacity. Finally, Tennet controls the recognition of program responsible parties [43].

DSOs are responsible for the construction, maintenance, management and development of the transportation and distribution networks for electricity between the high voltage grid and the customers. Since DSOs' are natural monopolies, their tariffs are regulated by the Dutch government. The Dutch distribution network is managed by eight DSOs which manage one or more separate distribution grids. DSOs' performance is evaluated by the Dutch regulation authority, the NMa.

\subsection{Program responsible parties (PRPS)}

A PRP is a legal entity that manages at least one physical connection to the grid and is the party that corresponds with Tennet. PRPs are responsible for forecasting their net demand, i.e., the difference between supply and demand passing through their physical connections (E-Program), and the quantity that will be transported through certain transmission lines from their connection (T-Prognosis). These responsibilities are called program responsibilities, and both forecasted quantities have to be ratified by Tennet on a daily basis [43]. There are two types of PRPs: (1) full PRPs and (2) trading PRPs. The former ones are allowed to take over connections of other parties, while the latter ones are only allowed to manage their own connections. With the introduction of the 1998 Electricity Act, all firms can buy and sell electricity in the market without having a physical connection. However, it is still obligatory to have a PRP permit or a contract with another party that has a PRP permit in order to trade electricity.

All market participants with a total power consumption or output larger than 2 MWs have to submit a T-prognosis to Tennet one day-ahead of the physical transaction. The T-prognosis has to be submitted before $2 \mathrm{PM}$ and it is used for multiple calculations by Tennet. PRPs also submit legally binding E-programs which are used for the settlement of imbalances. Each market participant with a connection has to maintain an E-program and need to submit it one day ahead of physical delivery before 2 PM every day. If a PRP does not submit an E-program, then its entire physical position is settled in the imbalance market [35].

PRPs are also obliged to pay imbalance costs. These costs are incurred during the day, whenever the realized net demand deviates from the forecasted demand submitted to Tennet in the E-program. For these deviations PRPs pay an imbalance cost

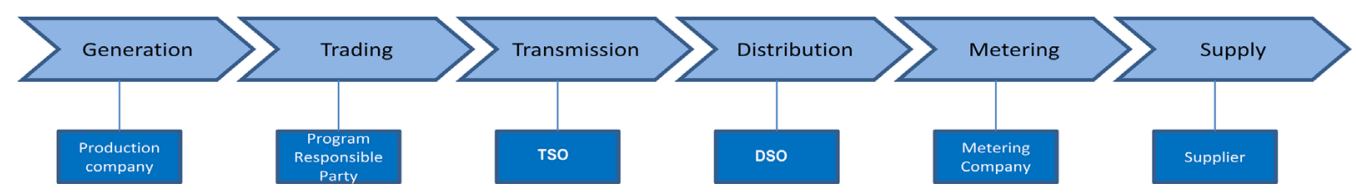

Fig. 1. Electricity supply chain [33]. 


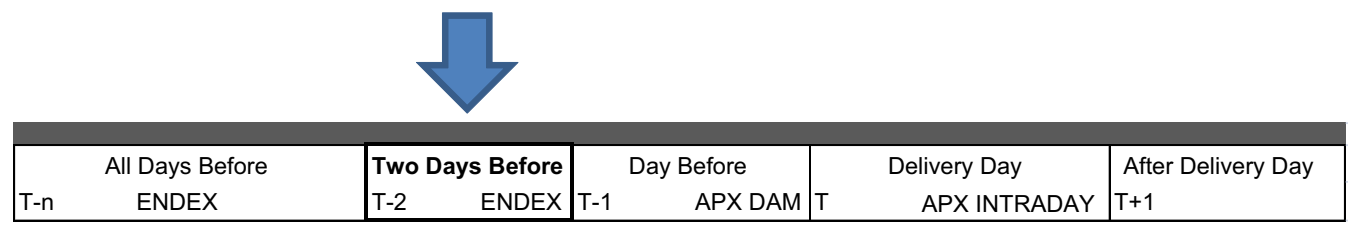

Fig. 2. Futures/ENDEX in the timeline of electricity markets.

depending on the amount of deviation and current market price of electricity during that specific moment. This introduces additional financial risks for the PRPs, and therefore they need an active risk management strategy. Finally, PRPs are also responsible for measuring the electricity flowing through their connection and communicating these quantities to Tennet. These data, combined with the information from Tennet are used for the settlement of imbalances [43].

\section{Financial market organization}

In this section, we describe the organization of the financial markets for trading electricity. Sections 2.1 and 2.2 are dedicated to discussing futures and spot markets, respectively. Then, in Section 2.3 we discuss the organization and the functioning of the imbalance market.

\subsection{ENDEX futures market}

Electricity spot and futures markets play a central role in the liberalization of the electricity markets by promoting price transparency, competition and risk management [44,5,8]. The Dutch electricity futures market was established in 1999 to support the liberalization of the Dutch market. Futures are traded on the organized exchange European Energy Derivatives Exchange (ENDEX). Futures contracts traded on ENDEX are physically settled. Hence, trading these contracts require a PRP permit since only the PRPs are allowed for the physical delivery of electricity. The delivery can be made to any connection in the Dutch network, since it is considered a single market. However, there are some physical constraints, especially in the western part of the Netherlands. In order to manage these transmission line constraints, Tennet implements a congestion management system $([37,40])$.

\subsubsection{Type of products}

The ENDEX futures market offers two standardized products based on the delivery hours of electricity. These contracts are also further classified according to their maturities as monthly, quarterly and yearly. In total there are nine futures contracts traded on $\operatorname{ENDEX}([11,12])$.

The first contract type is a "Dutch Power Base Load" future (DPBL). This future enables the physical delivery of $1 \mathrm{MWh}$ of electricity energy to the Dutch high voltage grid, from 00:00 on the first day of the delivery period until 24:00 on the last day of the delivery period. The second contract is called the "Dutch Power Peak Load" (8-20) (DPPL8-20), which delivers 1 MWh of electricity energy from 08:00 to 20:00 on all weekdays (including public holidays), during the delivery period to the Dutch high voltage grid. These individual contracts are traded for different durations and a fixed number of months, quarters and calendars forward (see [22] for pricing of these contracts). These contracts expire two days before the physical delivery as illustrated in Fig. 2. The delivery is served in the form of a day-ahead contract via the clearing house which is owned by APX. The position is fixed, and if a party would like to adjust its total short or long position, it can do so on the APX spot markets.
During the last ten years Dutch electricity futures trading reached to a significant volume and liquidity, hence providing a strong support for the liberalization of the electricity market in the Netherlands. According to ICE-ENRGY [18]: "A new total daily volume record for Dutch Power futures across Dutch Power Baseload and Dutch Power Peakload was also reached, with 3475 contracts traded on November 25, 2014."

\subsection{APX spot market}

The APX spot market consists of two separate markets: the Day-Ahead Market (DAM) and the Intra-day market (IDM). DAM is the larger of the two, and it is an auction type of market which determines the day-ahead electricity prices for each 24 hours of the next day. The second market, IDM, provides the participants with the ability to adjust their spot positions up to 5 min before the physical delivery of electricity. The Dutch IDM is coupled with the Belgian and Nord Pool Intraday markets as of March 2013.

\subsubsection{APX day-ahead market (DAM)}

DAM is a spot market in which firms can buy/sell spot electricity for physical delivery the next day. The format of the DAM is a two-sided, double-blind auction. That is, both buyers and sellers may place anonymous orders with different prices and quantities on an hourly basis. Those orders result in demand and supply curves for each hour of the next day [32,16]. There can be different types of orders, such as limit orders and block orders. Limit orders are single hourly orders with different price and quantity pairs, whereas block orders are multiple consecutive hourly orders. The market algorithm can accept limit orders fractionally, but the block orders are either accepted or rejected fully. Another type is profiled block orders, where the volume varies over the different hours.

The DAM opens at midnight on the day before the delivery (referred to as $T-1$, in Fig. 2), and all participants can make bids and offers for the delivery of electricity. Then, at 11:00 the TSOs publish the Available Transmission Capacity (ATC), which indicates how much capacity will be available during each hour of the delivery day between different countries. At 12:00 the auction closes and the inputs are used to start a matching algorithm called COSMOS. The algorithm takes all bids from the participants and uses the physical constraints imposed by the transmission lines (both nationally and internationally) to come up with the best clearing prices, maximizing social benefit (for more details see [13]). The result of the auction is published at 12:55 on the APX website and provides a reference for the other electricity markets.

Minimum and maximum prices on the DAM are -500 Euro/ MWh and 3000 Euro/MWh, respectively. APX is the central counterparty for all trades; all contracts are traded anonymously, and then cleared and settled on behalf of the members. Contracts traded on the exchange are fully collateralized as all members are required to pledge collaterals in the form of cash or letter of credit, in excess of outstanding exposures at all times. Fig. 3 shows the DAM in the timeline of electricity delivery. 


\subsubsection{APX intraday market}

Since 2006, APX has also operated an intraday market. After the DAM market closes, the hourly prices are announced to all market participants. However, during the time between the determination of the day-ahead positions and the physical delivery of electricity, the market participants may decide to update their physical positions. This can be done through the intra-day market.

The participants in this market can adjust their spot positions up to 5 minutes before the physical delivery of electricity. The cost of buying electricity in the intraday market is in general more expensive than the day-ahead market. This market is open $24 / 7$ and hence, with the new information the participants may adjust their positions immediately. The minimum price is $-99,999.90$ Euro/MWh and the maximum price 99,999.90 Euro/MWh. Fig. 4 below shows IDM in the timeline of the electricity markets.

\subsection{The imbalance market}

Maintaining grid balance is one of the primary functions of transmission system operators in liberalized electricity markets. In this regard, management of reserve capacity (imbalance market) both for additional electricity production and consumption is of great importance $[21,41]$. Successful liberalization of the electricity market requires creating an imbalance market (ancillary services) that is well integrated with spot trading and transmission capacity management [19]. In what follows, we first explain the details of the imbalance market.

\subsubsection{Electrical market details}

The power grid needs to be in balance at all times, i.e., the supply and demand of electricity must be equal in real time. When there is a surplus of power in the system, the frequency of electricity increases above the nominal value $(50 \mathrm{~Hz})$, and when there is a shortage it decreases below this level. If these deviations exceed a certain threshold then electrical equipments stop functioning or power outages occur. Since it is difficult to change electricity demand in real time, the steering is mostly done on the supply side of the balance, i.e. generators are ramped up and down to balance the fluctuation on the grid.

The TSO measures the imbalance of all PRPs based on their submitted E-programs. If a PRP deviates from its E-program (the total amount taken from or sent to the grid), TSO acts as an artificial market participant who buys (sells) the excess (shortage) electricity from (to) the PRP at a certain price in the imbalance market. This price is unknown upfront and is highly volatile.

In practice, since demand and supply of electricity cannot be accurately forecasted, there will always be some amount of imbalance on the grid, and these imbalances need to be managed. Therefore, the TSO has to ensure that it has customers that are willing to buy electricity if there is a market surplus, and producers who are willing to produce additional electricity whenever there is a market shortage. For this reason, TSO obligates the large producers to make bids and offers to buy and sell electricity in the imbalance market for every PTU. By placing bids in this market a producer can communicate the capacity it is willing to provide at the bid price. Hence, a buffer capacity is introduced for the total market. To ensure the liquidity in this market, the law obligates producers with more than $60 \mathrm{MW}$ of production capacity to make bids, and the TSO maintains yearly contracts for such spare capacity. The details of this process will be described in the next section. It is important to note that the balance is not maintained by the TSO itself, but by using the bids that have been submitted by the PRPs.

\subsubsection{Imbalance market bid-ladder}

The Dutch TSO, Tennet, organizes spare capacity in three categories; short-term adjustment capacity, reserve capacity and emergency capacity. Emergency capacity (EC) is obliged by law as a certain percentage of total capacity that each plant has available. This power is only called upon in emergency situations and it overrules all other spare capacities. Reserve capacity (RC) and Adjustment Capacity (AC) are both used to balance demand with supply. However, there are a number of important differences. First, RC takes longer to be activated than adjustment capacity. On the other hand, AC is used immediately and has a maximum response time of $30 \mathrm{~s}$. In addition, $\mathrm{RC}$ is always called in full, i.e., if a firm had placed an offer for $10 \mathrm{MW}$ and if this offer is activated in real time, then the full $10 \mathrm{MW}$ is called for a specific amount of time. AC on the other hand can be called upon partially, i.e., only $5 \mathrm{MW}$ of the offer can be called upon.

Every PRP with a capacity of $60 \mathrm{MW}$ or more has to make bids for $\mathrm{RC}$ or AC, for which they are prepared to increase or decrease production. Other PRPs can submit bids as well, though it is not obligatory. These bids are used to construct the imbalance bid-

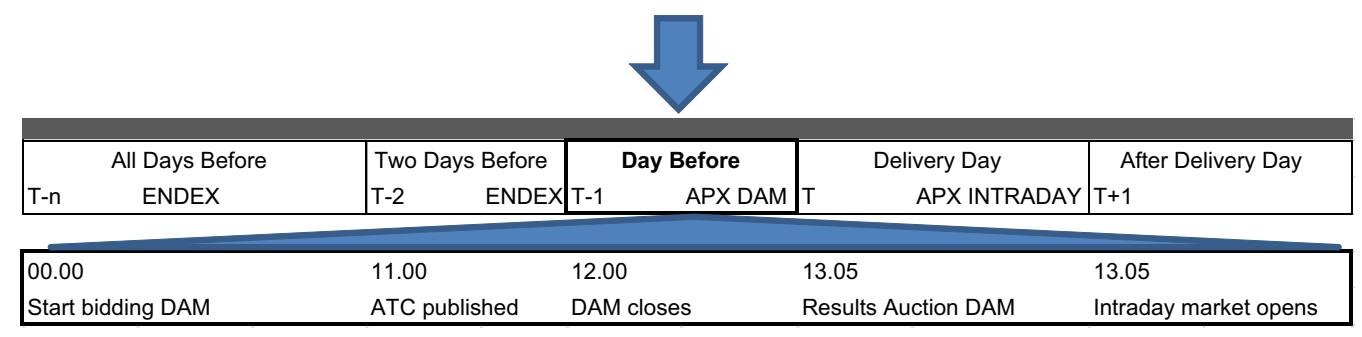

Fig. 3. DAM/APX in the timeline of electricity markets.

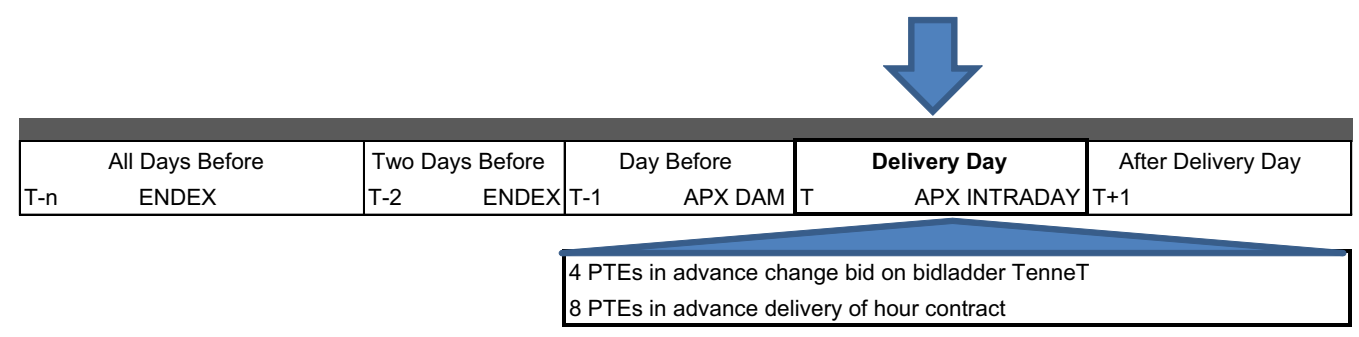

Fig. 4. IDM in timeline of electricity markets. 


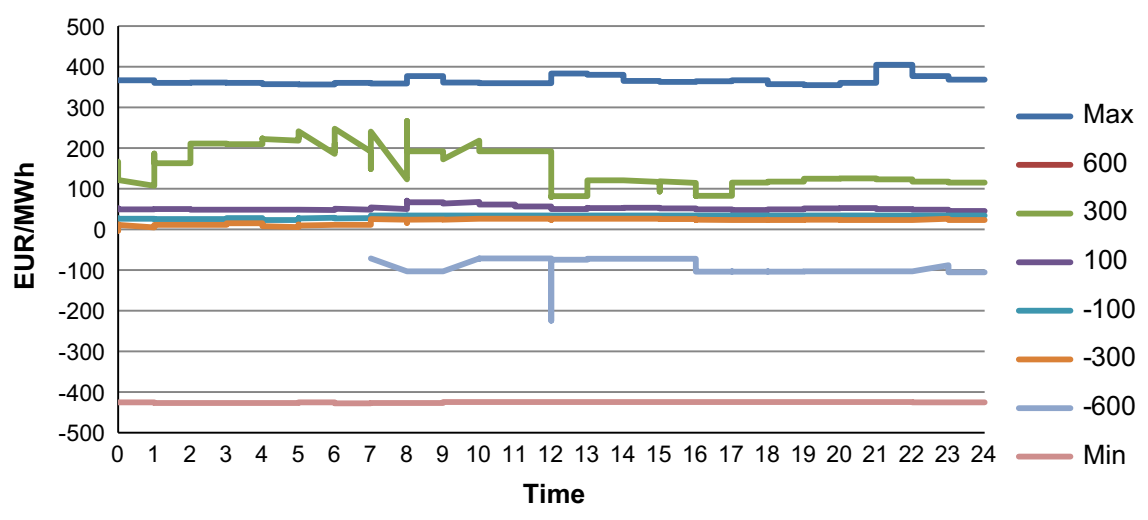

Fig. 5. Price bid ladder as published on 10 April 2014 at 4:12 PM [38].

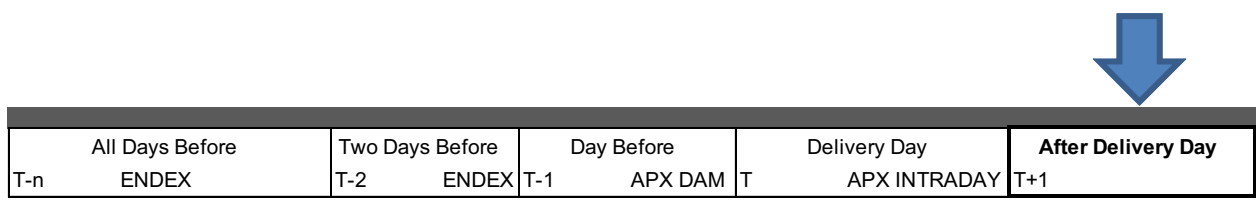

Fig. 6. Settlement of imbalance in the time line of electricity markets.

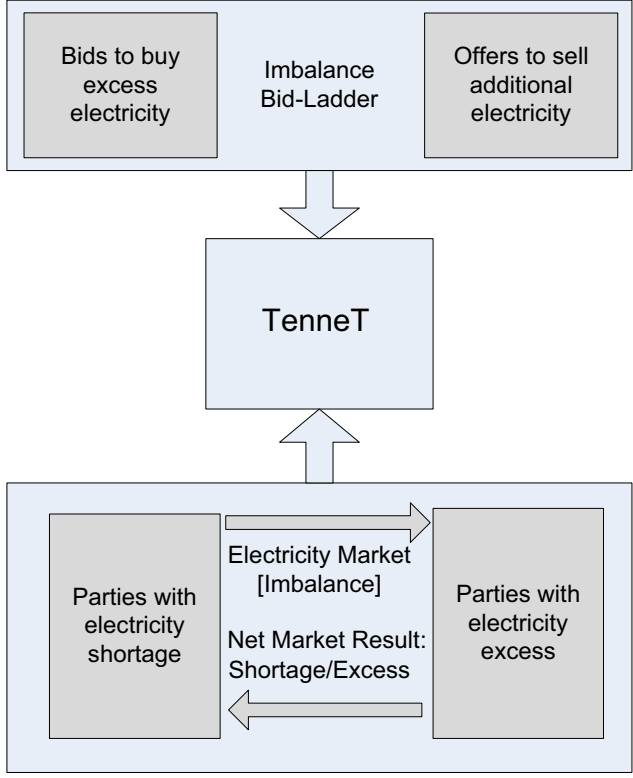

Fig. 7. Overview timeline of imbalance market.

ladder, from which the TSO selects the party to increase or decrease production. All bids are placed in multiples of $1 \mathrm{MW}$ and with a minimum size of 5 MW and maximum size of $200 \mathrm{MW}$. Also, the speed of upscaling has to be at least $7 \%$ per minute of the total offered capacity.

Fig. 5 shows the imbalance bid ladder in the Dutch Market on 10 April 2014 at 4:12 PM.

The figure above shows the bid-ladder for electricity at 4:12 PM on April 10, 2014. The lines indicate the current price that is asked for a certain increase/decrease in the supply of electricity. Each line represents a certain amount of electricity in the ladder. For instance, an increase of 100 Euro/MWh will cost 61 Euros at 11:00, while a $300 \mathrm{MW}$ correction will cost 200 Euro/MWh. The result is a bid-ladder for every PTU from which electricity can be bought or sold. The price of additional electricity increases exponentially as the total shortage increases. On the other hand, the price received for electricity decreases as total surplus increases, it can even become negative.

\subsubsection{Ex-post calculation of the imbalance cost}

After the physical delivery of electricity, imbalance amounts and the costs are calculated. This event is shown below in Fig. 6 on he timeline of electricity transactions.

As stated in the previous section, the TSO constructs a bid-ladder through which it can buy additional electricity and sell excess electricity whenever it is needed. Every $15 \mathrm{~min}$, the TSO measures the total imbalance that is present at every connection to the high voltage grid. Then, looking at these individual imbalances a market imbalance is constructed. This is the additional supply/demand that the TSO has to arrange in the imbalance market by activating the bids from the bid-ladder. This process is shown schematically in Fig. 7.

The TSO buys or sells the electricity using the bid-ladder. Every minute the TSO publishes the current amount of electricity that is sold or bought and the marginal price at which this is happening. This is a tool for market participants to monitor what the state of the market is, and to enable them to change their bids, based on developments of the market.

Fig. 8 shows the realized imbalance prices on April 10, 2014. The horizontal axis shows the PTUs indicating a specific time. The vertical axis shows the cost of imbalance at that specific moment. There are two prices, one that is used to settle a shortage (the red square) and one used to settle an overage (the blue diamond). The highest marginal bid to buy and lowest marginal bid to sell are used as the settlement price. All costs are quoted in EUR/MWh.

The calculation of the net cost to each PRP is based on a 15-min interval. First, the TSO calculates the total amount of net imbalance that occurred at each PRP. This results in a specific amount taken from the TSO or supplied to the TSO from that PRP. Second, the TSO looks at 


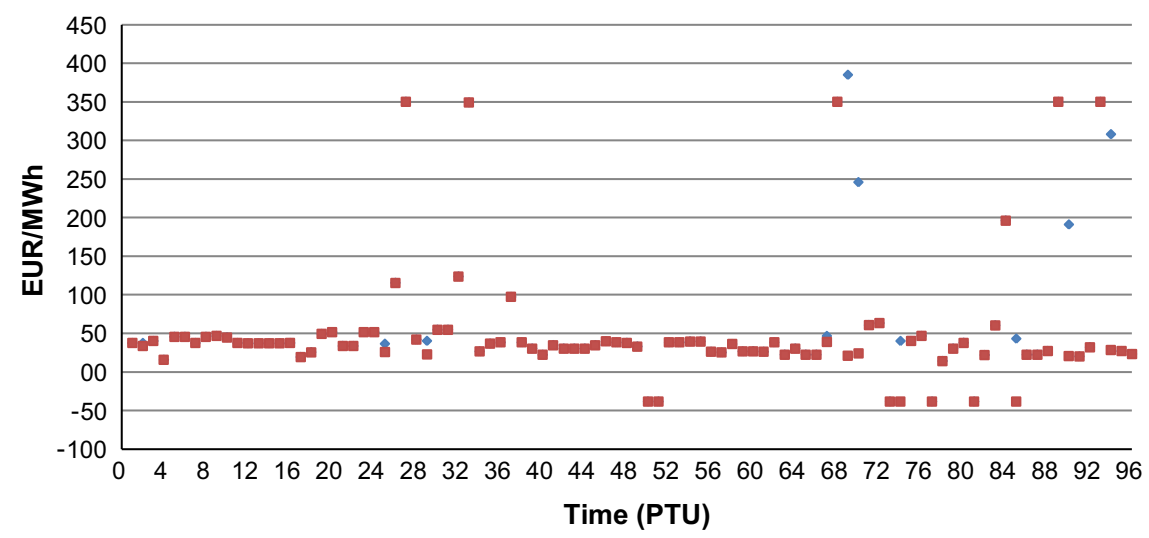

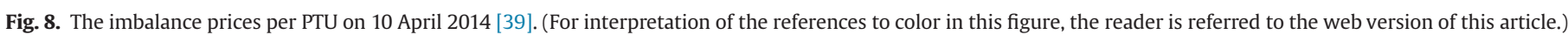

Table 1

Overview of different regulation states recognized by Tennet.

\begin{tabular}{ll}
\hline Regulation State & Description \\
\hline 0 & No shortage and surplus in the system \\
+1 & Tennet has been buying additional electricity exclusively; or, Tennet has been continuously upscaling \\
-1 & Tennet has been selling additional electricity exclusively; or Tennet has been downscaling continuously \\
2 & Tennet has been both selling and buying electricity \\
\hline
\end{tabular}

the bids and offers activated, and uses the highest bid that was paid for additional electricity and the lowest bid activated to sell electricity. These two prices are used to pay the suppliers of demand and capacity.

Based on the direction of imbalance there are 4 regulation states in each PTU (see Table 1). If the regulation state is zero, then no additional electricity is bought or sold. In this case, small imbalances are settled using the average price when buying and selling. Hence, a 'fair' price is used that does not deviate significantly from the current market price. When the regulation state is ' -1 ' or ' +1 ', the TSO needs to buy or sell additional electricity exclusively. This means that the market had deviated advantageously to one side only. If this is the situation, all imbalances are settled using a single price. Therefore, in this regulation state there are both winners and losers. The winners are the PRPs that had an imbalance that was opposite of the market imbalance. When the market has shortage of electricity, the parties with excess electricity will sell their excess to the TSO at a high price, making a profit on their excess imbalance. On the other hand, the parties with a shortage will pay a high price to recover their shortage.

Finally, if the regulation state is a '2', then both corrections happen, and both buying of electricity from the TSO and selling electricity to the TSO take place at a cost compared to the market price. Note that selling to the TSO may even result in a negative price, indicating that additional money needs to be paid for delivering electricity. This pricing behavior is shown in Fig. 9.

After the regulation state and the resulting prices have been determined, all PRPs are charged for their net imbalances. A PRP that has multiple connections only pays for the net imbalance. Netting the imbalance over time is not possible. The profit that the TSO earns on these transactions (small deviations are possible) is returned to the market participants in the form of discounts in the next year. Hence, the TSO does not profit from these transactions and the imbalance market offers a zero-sum game.

\section{Quantitative analysis of APX spot and imbalance prices}

In this section, we provide a quantitative analysis of day-ahead spot and imbalance prices for the Dutch electricity market.

\subsection{Overview of spot prices}

We first plot the DAM spot prices between $1 / 1 / 2002$ and 4/9/ 2011 in Fig. 10 below. We observe that, similar to other commodities, the prices have a strong tendency to revert to mean. In addition, multiple price spikes are apparent, which are mainly caused by low temperatures during the winter period, and droughts during the summer period (Boogert and Dupont [4]).

Next, in Fig. 11 we plot the average prices for each of the $24 \mathrm{~h}$ of the day. The figure demonstrates that the spot prices are more likely to spike during the early morning and early evening, i.e., the standard deviation of the price also increases during peak hours. From Fig. 11 it is clear that the average spot prices and the volatility of the prices tend to rise during peak hours and decline during off-peak hours. The difference between the mean and median spot prices also increases during the peak hours indicating large spikes during these hours. The occurrence of spikes during the peak hours is not very surprising since the market demand approaches to available total capacity during these hours.

We next analyze the frequency of price spikes (i.e., prices above or below a certain standard deviations of the mean price) for each hour of the day in Fig. 12. We observe that upward price spikes tend to happen between 6-11 AM and 5-7 PM. This pattern can be explained by Dutch working habits, industrial production and electricity generation capacity and technology during these hours. In particular, in the mornings energy consumption suddenly ramps-up as people wake up and start their work. The same line of argument also applies at the end of the day when people are returning home from work. 


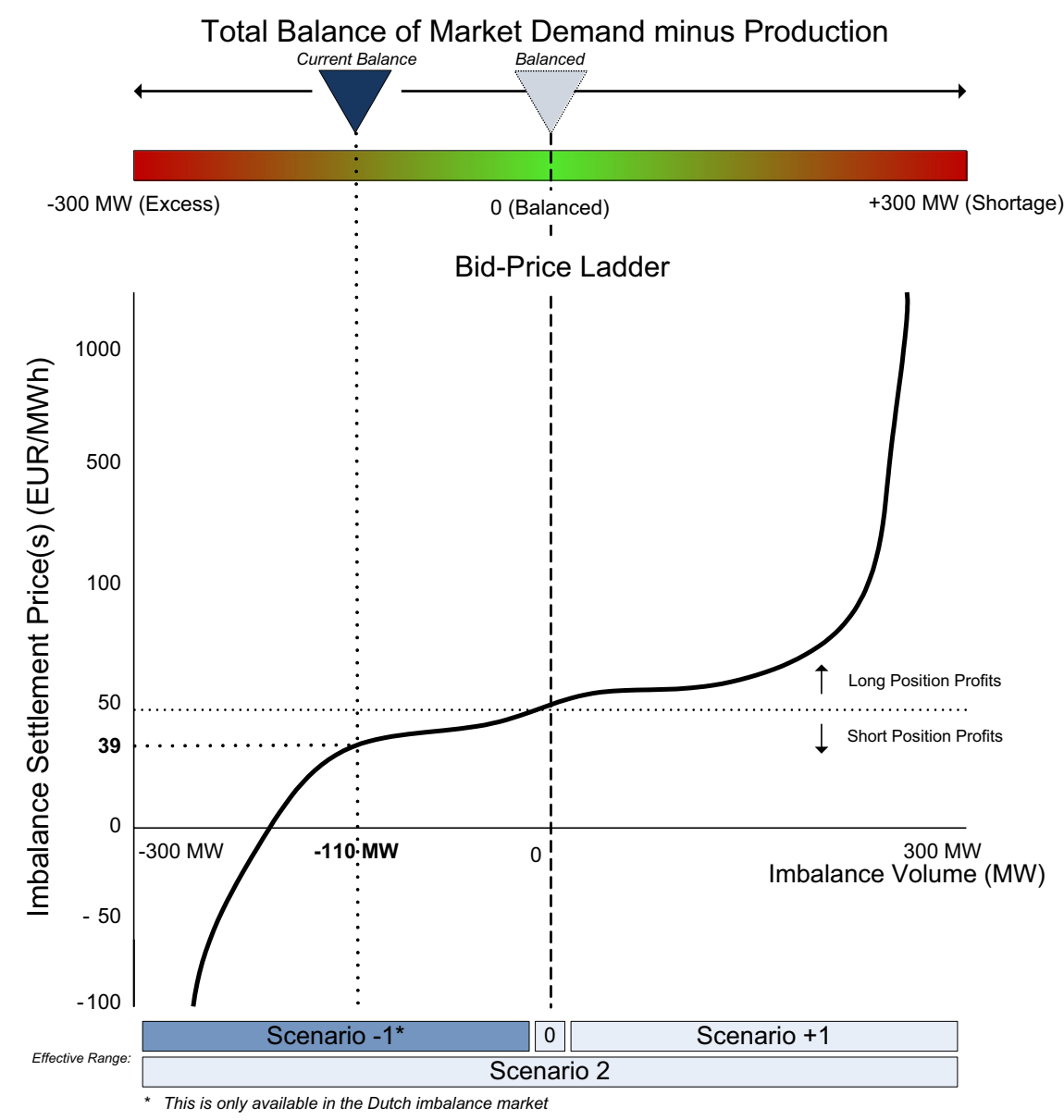

Fig. 9. Imbalance management.
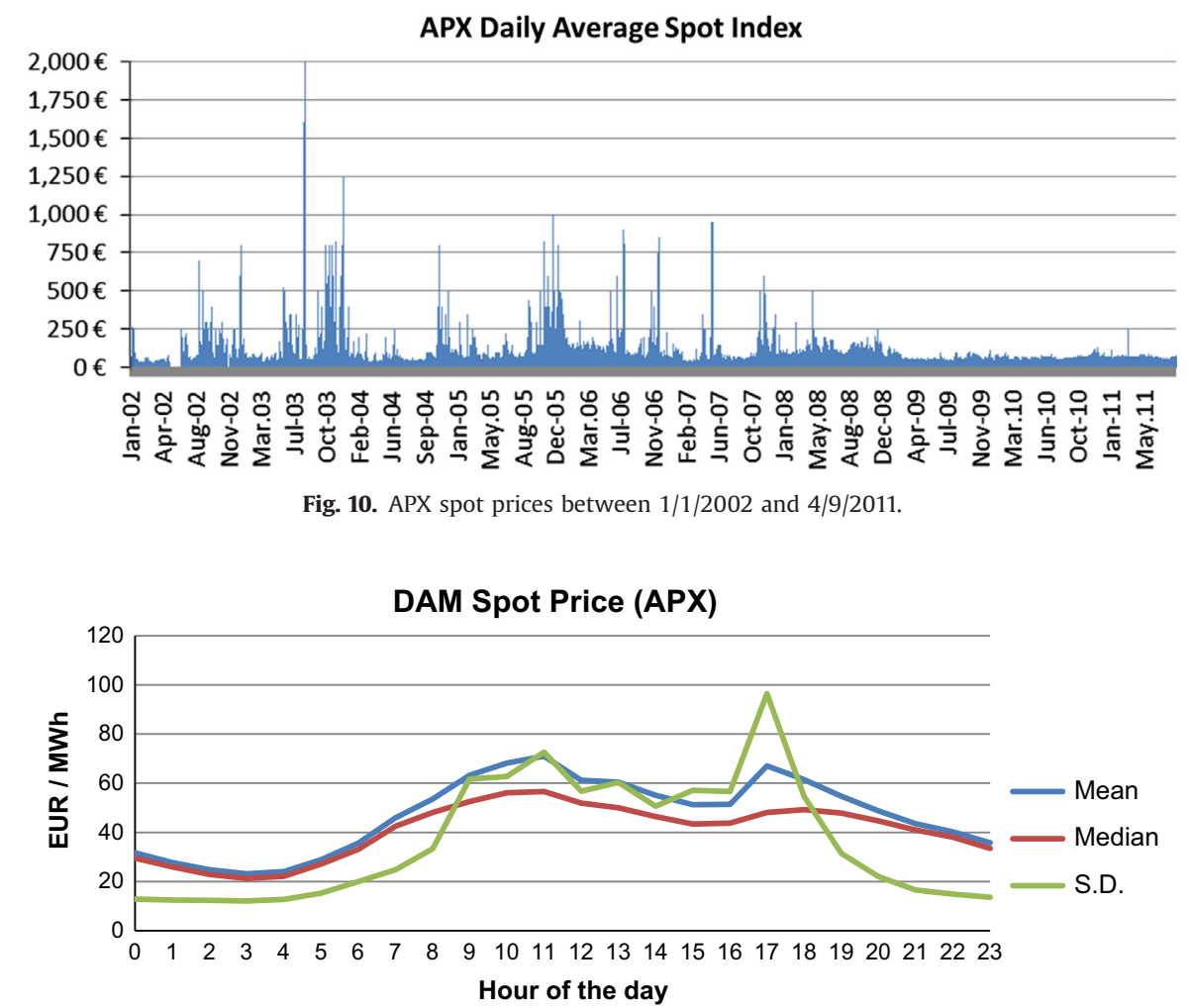

Fig. 11. Overview of main statistics for the hourly spot prices between 1/1/2002 and 4/9/2011. 


\section{Observations lower than 2SDs below the mean}

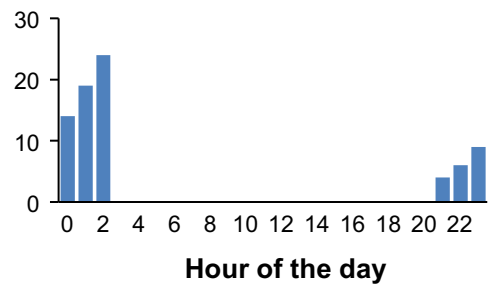

\section{Observations higher than 2SDs above the mean}

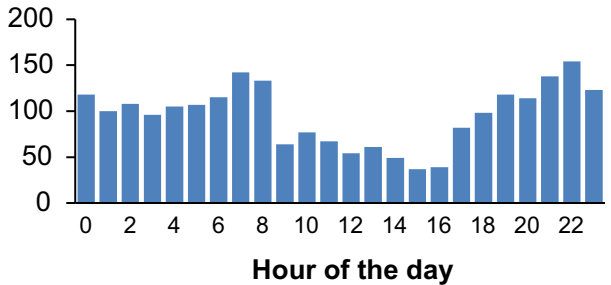

Observations higher than 3SDs above the mean

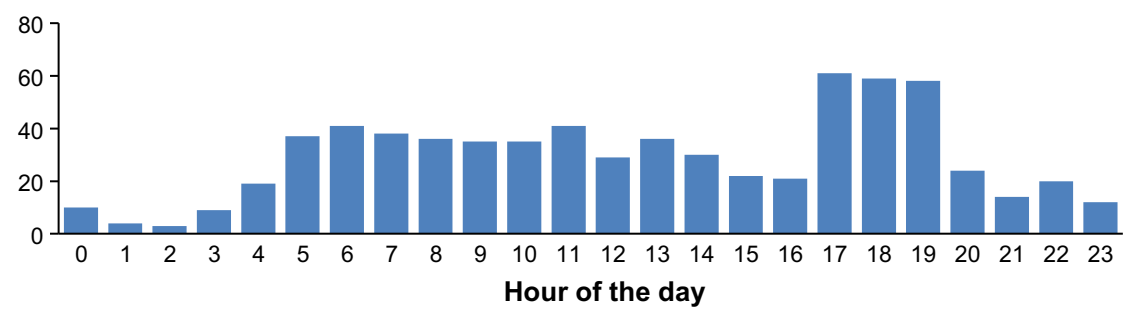

Fig. 12. Frequency of price spikes for each hour of the day between 1/1/2002 and 4/9/2011.

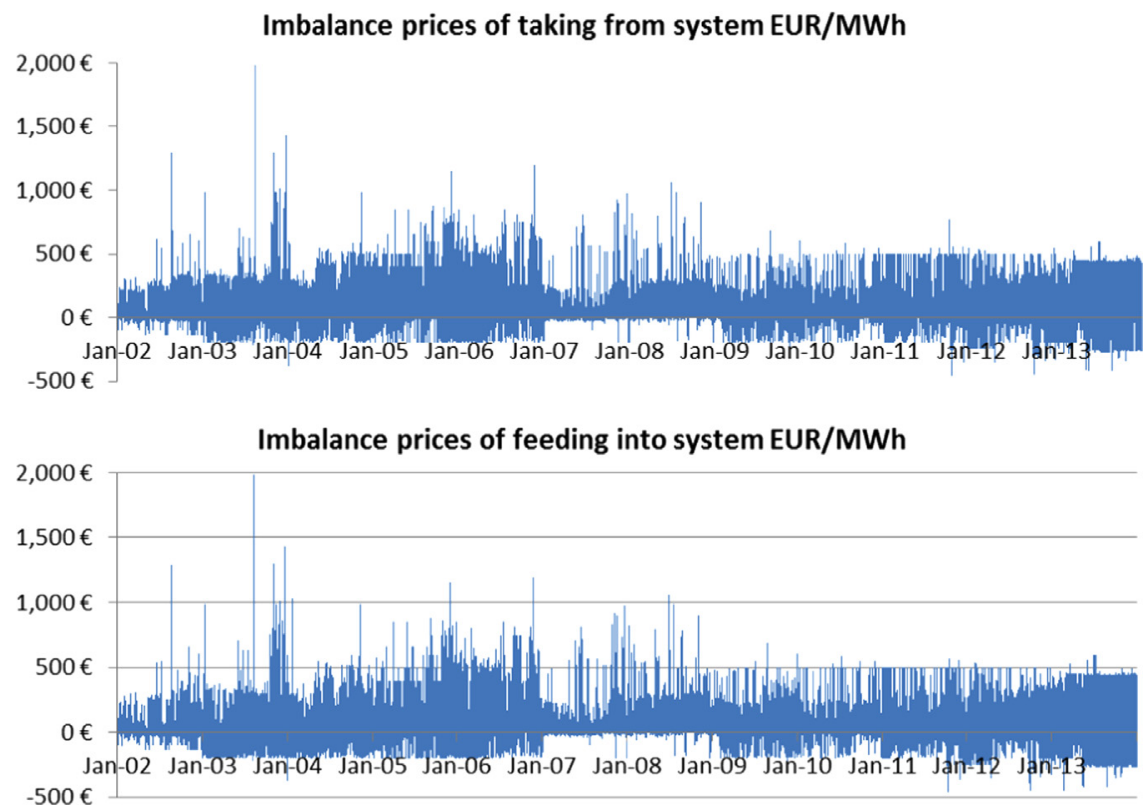

Fig. 13. Imbalance prices between $1 / 1 / 2002$ and $12 / 31 / 2013$.

Downward spikes also occur. However, as expected, downward spikes are less often and smaller in magnitude. They occur only in off-peak hours, when production is plentiful and demand is at its lowest level.

\subsection{Overview of imbalance prices}

Imbalance prices are paid and received by PRPs who deviate from their E-programs. PRPs with deficits buy electricity from the system so they have to pay a settlement price for their imbalances. Similarly, PRPs with surpluses are overfeeding electricity into system so they receive additional payment (which can be negative) because of their surpluses. However, the settlement prices can substantially fluctuate depending on the system balance itself. In particular, if the overall market is in deficit, then this can be beneficial to PRPs with surpluses. They can settle for their surpluses well above the day-ahead market prices in the imbalance market. However, PRPs with deficits could suffer because of these high prices. The reverse logic applies when the overall market has a surplus. In Fig. 13, we show imbalance prices between $01 / 01 / 2002$ and $12 / 31 / 2013$. We observe that the prices can occasionally become negative. This indicates a large surplus of supply during these hours.

It is also of interest to investigate the frequency of overall market overages and shortages. Our analyses reveal that, during the last 12 years, $47 \%$ of the time the system had an overage (regulation state +1 ) and $34 \%$ of the time the system had a shortage (regulation state -1 ). In addition $18 \%$ of the time, both cases happened at the same PTU (regulation state 2). Finally, 1\% of the time the system was in balance and no additional trading was needed in the imbalance market (regulation state 0 ). These figures indicate that system overages happen significantly more often than shortages indicating 
Table 2

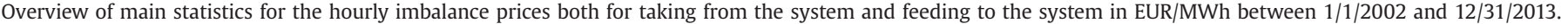

\begin{tabular}{|c|c|c|c|c|c|c|c|c|c|c|c|c|c|}
\hline \multicolumn{7}{|c|}{ Summary statistics for taking from the system } & \multicolumn{7}{|c|}{ Summary statistics for feeding to the system } \\
\hline Hours & Mean & Min & Med. & Max & S.D. & Skew. & Hours & Mean & Min & Med. & Max & S.D. & Skew. \\
\hline 0 & 38.8 & -345.7 & 33.0 & 600.0 & 59.6 & 2.4 & 0 & 27.0 & -450.7 & 21.8 & 600.0 & 53.5 & 2.1 \\
\hline 1 & 34.9 & -422.3 & 32.0 & 600.0 & 46.6 & 3.4 & 1 & 28.5 & -422.3 & 25.6 & 600.0 & 43.3 & 2.9 \\
\hline 2 & 30.8 & -256.0 & 30.6 & 600.0 & 31.6 & 3.6 & 2 & 27.2 & -256.0 & 26.8 & 600.0 & 29.8 & 2.7 \\
\hline 3 & 28.2 & -299.6 & 29.0 & 488.4 & 26.3 & 0.9 & 3 & 25.6 & -356.7 & 25.8 & 488.4 & 25.9 & 0.4 \\
\hline 4 & 27.4 & -460.0 & 28.0 & 499.6 & 31.7 & 0.5 & 4 & 23.0 & -460.0 & 22.1 & 499.6 & 30.9 & -0.2 \\
\hline 5 & 34.6 & -449.6 & 30.3 & 750.0 & 57.2 & 2.1 & 5 & 23.5 & -449.6 & 19.0 & 750.0 & 52.5 & 1.4 \\
\hline 6 & 50.3 & -355.6 & 36.2 & 750.0 & 90.9 & 1.4 & 6 & 30.3 & -359.6 & 18.0 & 1036.6 & 85.3 & 1.4 \\
\hline 7 & 67.5 & -345.6 & 46.9 & 999.0 & 106.6 & 1.3 & 7 & 45.6 & -351.6 & 28.1 & 999.0 & 103.6 & 1.5 \\
\hline 8 & 66.2 & -378.0 & 48.0 & 1784.0 & 93.1 & 3.2 & 8 & 51.8 & -378.0 & 36.6 & 1784.0 & 90.2 & 2.9 \\
\hline 9 & 68.4 & -254.4 & 50.0 & 1784.0 & 83.0 & 5.3 & 9 & 60.6 & -254.4 & 41.8 & 1784.0 & 80.7 & 5.6 \\
\hline 10 & 70.7 & -200.0 & 50.0 & 1784.0 & 88.0 & 5.8 & 10 & 65.8 & -253.5 & 45.2 & 1784.0 & 86.9 & 6.0 \\
\hline 11 & 63.8 & -417.2 & 47.0 & 1784.0 & 79.3 & 6.6 & 11 & 59.3 & -417.2 & 41.8 & 1784.0 & 77.6 & 6.9 \\
\hline 12 & 62.4 & -200.0 & 45.1 & 1963.5 & 79.9 & 7.1 & 12 & 57.9 & -200.0 & 40.0 & 1963.5 & 79.1 & 7.3 \\
\hline 13 & 59.2 & -298.6 & 43.6 & 1963.5 & 76.9 & 7.7 & 13 & 54.9 & -298.6 & 39.1 & 1963.5 & 75.6 & 8.1 \\
\hline 14 & 54.1 & -250.5 & 40.2 & 1903.2 & 73.5 & 9.0 & 14 & 50.3 & -250.5 & 36.5 & 1903.2 & 72.3 & 9.4 \\
\hline 15 & 50.7 & -200.0 & 39.4 & 1984.0 & 69.6 & 11.4 & 15 & 45.7 & -200.0 & 34.6 & 1984.0 & 67.0 & 12.2 \\
\hline 16 & 52.8 & -250.5 & 40.0 & 1984.0 & 75.7 & 7.8 & 16 & 45.7 & -251.5 & 33.9 & 1984.0 & 74.2 & 8.7 \\
\hline 17 & 68.4 & -250.5 & 42.6 & 1435.0 & 103.9 & 4.0 & 17 & 57.1 & -251.5 & 34.7 & 1435.0 & 99.4 & 4.3 \\
\hline 18 & 63.6 & -250.1 & 43.6 & 903.3 & 81.4 & 3.0 & 18 & 53.9 & -250.1 & 36.3 & 903.3 & 76.3 & 3.3 \\
\hline 19 & 59.5 & -408.6 & 43.0 & 840.1 & 72.8 & 2.9 & 19 & 48.5 & -408.6 & 34.6 & 840.1 & 67.9 & 3.2 \\
\hline 20 & 50.8 & -408.2 & 37.4 & 750.0 & 65.4 & 2.7 & 20 & 38.9 & -408.2 & 29.3 & 750.0 & 58.5 & 2.8 \\
\hline 21 & 49.6 & -359.1 & 36.0 & 750.0 & 68.7 & 2.6 & 21 & 36.1 & -359.1 & 27.0 & 750.0 & 60.4 & 2.5 \\
\hline 22 & 51.2 & -389.7 & 35.0 & 750.0 & 83.1 & 2.5 & 22 & 33.0 & -389.7 & 22.9 & 750.0 & 69.9 & 2.5 \\
\hline 23 & 43.3 & -389.7 & 33.1 & 750.0 & 74.8 & 2.1 & 23 & 23.5 & -389.7 & 18.0 & 662.0 & 61.9 & 1.5 \\
\hline Total & 52.0 & -460.0 & 38.2 & 1984.0 & 75.8 & 4.6 & Total & 42.2 & -460.0 & 31.1 & 1984.0 & 71.9 & 5.0 \\
\hline
\end{tabular}

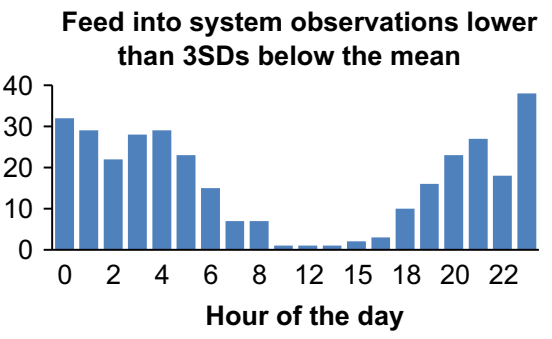

Feed into system observations higher than 3SDs above the mean

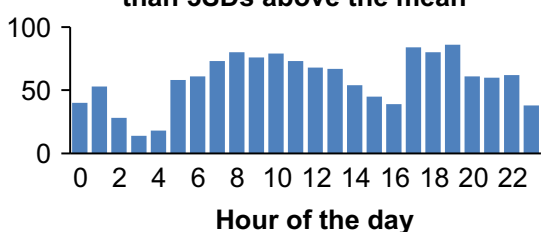

Take from system observations lower than 3SDs below the mean

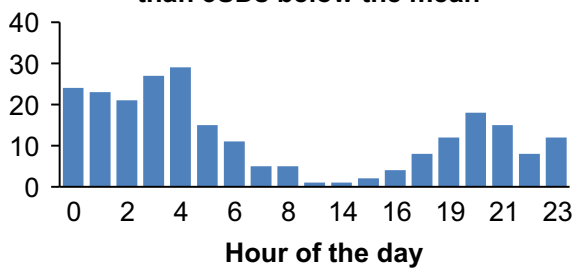

Take from system observations higher than 3SDs above the mean

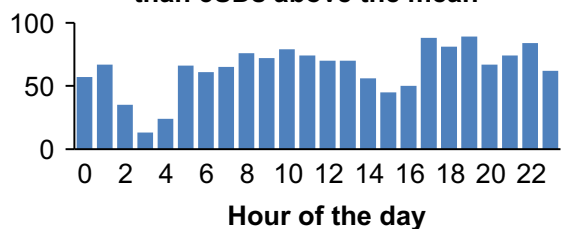

Fig. 14. Frequency diagram of number of significant deviations of more than 3 sigma of that specific hour based on data from the imbalance market from 01/2002-12/2013.

that the market, on average, tends to buy more than what is necessary. This could be explained by the skewness of the prices together with the risk attitude of the market participants. In particular, prices are positively skewed implying larger upward price spikes relative to downward spikes. This leads the market participants to take excess positions relative to the mean demand. In what follows we further explore buying (taking from the system) and selling (feeding to the system) prices in the imbalance market.

Table 2 shows the summary statistics of hourly imbalance prices. There are two prices in the imbalance market: one is to take (buy) from the system and the other is to feed (sell) to the system. For all hours of the day, taking from the system has a higher mean price and standard deviation than feeding to the system. The average price for taking from the system was $52 \mathrm{EUR} / \mathrm{MWh}$ while the price for feeding to the system was $42.2 \mathrm{EUR} / \mathrm{MWh}$.
In addition, when we compare imbalance prices with the DAM spot prices, we observe that on average, taking from the system is 4.94 EUR/MWh higher than the day-ahead market prices whereas feeding to system is $4.79 \mathrm{EUR} / \mathrm{MWh}$ lower than the day-ahead prices. These are the average risk premiums in the imbalance market relative to the day-ahead market. Unlike usual commodity and stock markets we observe two risk-premiums one for selling and one for buying electricity in the imbalance market. This is because $18 \%$ of the time the system observes a regulation state 2 in which buying and selling prices diverge. This happens because in regulation state 2 both an overage and underage happens during the same PTU and the system operator both buys and sells electricity at different prices.

Finally, we show the frequency of 3-sigma and higher price spikes in the imbalance market in Fig. 14. Price spikes for taking 
from the system has a similar pattern with feeding to the system. Prices for taking from the system tend to generate more upward spikes than the prices for feeding to the system. Similar to the dayahead market, upward spikes also occur from 6 to $10 \mathrm{AM}$ and from 5 to 7 PM. This pattern can be explained by the power-up and power-down phases of the working day.

In addition, although day-ahead market prices do not present any downward spikes below three standard deviations of the mean; the imbalance market does have such spikes. This makes the imbalance market prices more volatile than the day-ahead prices. These downward spikes happen only in off-peak hours when the demand is very low.

\section{Discussion}

We examined the organization and the functioning of the liberalized Dutch electricity markets including the futures, dayahead, intra-day and imbalance markets. First, we described the liberalization and the organization of the Dutch electricity supply chain and the role of the main market participants including the transmission system operator, distribution system operators, program responsible parties and metering companies. We then delineated the organization of financial trading and clearing mechanism of electricity through the organized futures exchange (The European Energy Derivatives Exchange), and the spot market (Amsterdam Power Exchange) which includes the day-ahead market and intra-day markets. We also detailed the functioning of the imbalance market and reserve capacity management in the Netherlands.

We also conducted an exploratory analysis of the Dutch electricity prices in the day-ahead and imbalance markets. We observed that price spikes both in the day-ahead and imbalance markets usually occur around 6-10 AM and 5-7 PM. Nevertheless, the imbalance prices are significantly more volatile than the dayahead prices. In particular, although day-ahead market prices do not present any downward spikes below three standard deviations of the mean, the imbalance market does have such spikes.

A close examination of the imbalance market revealed that during the last 12 years, $47 \%$ of the time the system had an overage (regulation state +1 ) and $34 \%$ of the time the system had a shortage (regulation state -1 ). In addition $18 \%$ of the time, both cases happened at the same PTU (regulation state 2). Finally, $1 \%$ of the time the system was in balance and no additional trading was needed in the imbalance market (regulation state 0 ). These figures conclude that system overages happened significantly more often than shortages, pointing out that the market tends to buy more than what is necessary. This could be explained by the skewness of the prices together with the risk attitude of the market participants.

On the other hand, there are two prices in the imbalance market: one is to take (buy) from the system and the other is to feed (sell) to the system. The average price for taking from the system was $52 \mathrm{EUR} / \mathrm{MWh}$ while the price for feeding to the system was $42.2 \mathrm{EUR} / \mathrm{MWh}$. When we compared these figures with the average DAM spot prices, we observed that on average, taking from the system is $4.94 \mathrm{EUR} / \mathrm{MWh}$ higher than the day-ahead market prices whereas feeding to system is $4.79 \mathrm{EUR} / \mathrm{MWh}$ lower than the day-ahead prices. These are the average risk premiums in the imbalance market relative to the day-ahead market. Unlike usual commodity and stock markets we observed two riskpremiums; one for selling and one for buying electricity in the imbalance market. This is because $18 \%$ of the time the system observes a regulation state 2 in which buying and selling prices diverge.
When we look at the spot and imbalance prices as a time series, we also observe a clear reduction is price spikes and average prices during the course of the liberalization efforts. Especially during early 2000s there were frequent spikes in prices which may be attributed to the fast transition in the electricity markets. This is in agreement with the predictions of Joskow [19]. As the transition of the electricity markets are completed by early 2010s, the price spikes gradually disappeared. This is also in line with the increased liquidity and trading volume in spot and futures markets.

\section{Conclusions and policy implications}

Our analysis reveals key insights to the market participants as well as the policy makers in the Dutch electricity market. These implications are summarized as follows.

Implications on risk management for market participants and policy makers: We observe that upward price spikes in the dayahead market usually occur during the peak hours while the downward spikes usually occur during the off-peak hours. This implies that the hedging behavior of the market participants would be different during off-peak and peak hours.

The risk in the day-ahead market can be hedged using the futures market. In particular, risk-averse market participants would demand more protection during the peak hours relative to off-peak hours. This would lead the firms to over-hedge (more than the expected physical exposure) during the peak-hours and under-hedge (less than the expected physical exposure) during the off-peak hours. An appropriate over-hedging policy for the peakhours can be constructed using the Dutch Power Peak Load contracts in the futures market. However, the Dutch futures market does not provide futures contracts delivering exclusively during the off-peak hours. Instead there is a Dutch Power Base Load contract which delivers during all $24 \mathrm{~h}$ of the day. Hence, the firms can only use Dutch Power Base Load contracts to hedge their off-peak hour risks in the day-ahead market. However, since these contracts are not exactly tailored to off-peak hours, they are not efficient for hedging the risk for the off-peak hours. In this regard, introducing off-peak-hours futures contracts would benefit the market participants. Nevertheless, the policy makers face a dilemma here. Although introducing such contracts would better hedge the risk during the off-peak hours, it will, however, reduce the liquidity of the base load contracts.

Market participants and policy makers should be more cautious about upward price spikes than downward price spikes: We observe that upward price spikes occur more often than downward price spikes in the electricity markets. In addition, we observe numerous upward price spikes above three standard deviation of the mean price in the day-ahead market. However, there were no downward price spikes below three standard deviation of the mean. This implies that a short position in the day-ahead market is riskier than a long position for the market participants.

Imbalance market is significantly more risky than the day-ahead market: The magnitude of price spikes in the imbalance market is much larger than the magnitude of the spikes in the day-ahead market. In addition, the risk premium for the imbalance market relative to the day-ahead-market is around $10 \%$. Hence, trading electricity the imbalance market is both more risky and expensive in the imbalance market relative to day-ahead market. This implies that the risk-averse market participants should use the imbalance market as a last resort when trading electricity.

The market tends to over-buy in the imbalance market: In particular, during the last 12 years, $47 \%$ of the time the system had an overage (regulation state +1 ) and $34 \%$ of the time the system had a shortage (regulation state -1 ). This implies that the 
market participants are more worried about an upward price spike than a downward price spike.

The average price of buying and selling electricity diverges in the imbalance market: During the last 12 years, $18 \%$ of the time buying and selling prices during a PTU were different. This happens when the market experiences both an overage and underage during a PTU. We expect that as the renewable's share in electricity generation increases, the frequency of such regulation states will increase, as the volume of renewable generation is highly volatile. To mitigate this issue, the policy makers may reduce the PTU size.

With the completion of the liberalization of the electricity markets, the volatility of spot and imbalance electricity prices have decreased. Hence liberalized markets in the Netherlands provided the investors and other market participants with a more stable economic environment in which they can better forecast future prices and evaluate investment plans. According to World Economic Forum the Netherlands scores 0.88 in energy access and security index and ranked among the top countries in the world [42].

\section{References}

[1] APX, 2014. APX group power spot exchange, aggregated curves. 〈http://www. apxgroup.com/market-results/apx-power-nl/aggregated-curves/ $\rangle$.

[2] Argueso J. From regional markets to a single European market. In: Proceedings of the 7 th international conference on the European Energy Market (EEM), IEEE; 2010

[3] Boisseleau F. The role of power exchanges for the creation of a single European electricity market: market design and market regulation. The Netherlands: Univerisite Paris IX Dauphine, Delft University Press; 2004.

[4] Boogert, Alexander, Dominique Dupont. The nature of supply side effects on electricity prices: The impact of water temperature. Economics Letters 2005;88(1):121-5.

[5] Botterud A, Kristiansen T, Ilic MD. The relationship between spot and futures prices in the Nord Pool electricity market. Energy Econ. 2010;32(5):967-78.

[6] Damme EV. Liberalizing the Dutch electricity market: 1998-2004. Energy J. 2005:155-79.

[7] De Nooij M, Baarsma B. Divorce comes at a price: an ex ante welfare analysis of ownership unbundling of the distribution and commercial companies in the Dutch energy sector. Energy Policy 2009;37(12):5449-58.

[8] Deng SJ, Oren SS. Electricity derivatives and risk management. Energy 2006;31 (6):940-53.

[9] Derinkuyu K. On the determination of European day ahead electricity prices: the Turkish case. Eur. J. Oper. Res. 2015;244(3):980-9.

[10] Derinkuyu K, Tanrisever F, Baytugan F, Sezgin M. Combinatorial auctions in Turkish day ahead electricity market. In: Sabuncuoglu I, Kara BY, Bidanda. B, editors. Industrial engineering applications in emerging countries. CRC Press; 2015. p. 49-64.

[11] ENDEX A. Power market instrument specifications v4.0. Amsterdam: APX ENDEX; 2011

[12] ENDEX A. Price settlement procedure. Amsterdam: APX ENDEX; 2014.

[13] EPEXSPOT. 2014. 〈http://static.epexspot.com/document/20015/COSMOS_pub lic description.pdf $\rangle$.

[14] Hall, 2014. 〈http://www.platts.com/latest-news/electric-power/brussels/eu-ex changes-plan-intraday-power-market-coupling-26695758>, 2012.

[15] Haldrup, Niels, Morten Ørregaard Nielsen. A regime switching long memory model for electricity prices. Journal of econometrics 2006;135(1):349-76.

[16] Hortacsu A, Puller SL. Understanding strategic bidding in multi-unit auctions: a case study of the Texas electricity spot market. RAND J. Econ. 2008;39 (1):86-114.

[17] Hunt S. Making competition work in electricity. New York: John Wiley\&Sons, Inc.; 2002.

[18] ICE-ENRGY. 2014. 〈http://www.businesswire.com/news/home/20141126005340/ en/ICE-Endex-Achieves-Daily-Volume-Records-TTF\#.VQqF201WE6Y).
[19] Joskow P. Lessons learned from electricity market liberalization. Energy J 2008;29(2):9-42.

[20] Kemfert C, Barbu D, Kalashnikov V. Economic effects of the liberalization of the European electricity market - simulation results of a gam theoretic modeling concept. IEWT Internationale Energiewirtschaftstagung Wien, Vienna; 2003.

[21] Klessmann C, Nabe C, Burges K. Pros and cons of exposing renewables to electricity market risks-a comparison of the market integration approaches in Germany, Spain, and the UK. Energy Policy 2008;36(10):3646-61.

[22] Kristiansen T. Pricing of monthly forward contracts in the Nord Pool market. Energy Policy 2007:35(1):307-16.

[23] Looijestijn-Clearie A. Breaking up is hard to do: Dutch unbundling legislation and the free movement of capital. Eur. Bus. Organ. Law Rev. 2014;15 (03):337-55.

[24] Madani M, Van Vyve M. Computationally efficient MIP formulation and algorithms for European day-ahead electricity market auctions. Eur. J. Oper. Res. 2015;242(2):580-93.

[25] Martin A, Müller JC, Pokutta S. Strict linear prices in non-convex European day-ahead electricity markets. Optimization Methods Softw. 2014;29 (1):189-221.

[26] Meeus L, Vandezande L, Cole S, Belmans R. Market coupling and the importance of price coordination between power exchanges. Energy 2009;34:228-34.

[27] Möller, Christoph, Svetlozar T. Rachev, Frank J. Fabozzi. Balancing energy strategies in electricity portfolio management. Energy Economics 2011;33(1): 2-11.

[28] Soares I, Sarmento P. Does unbundling really matter? The telecommunications and electricity cases (No. 380). Universidade do Porto, Faculdade de Economia do Porto; 2010.

[29] Squicciarini G, Cervigni G, Perekhodtsev D, Poletti C. The integration of the European electricity markets at a turning point: from the regional model to the Third Legislative Package. 2010.

[30] Steiner F. Regulation, industry structure, and performance in the electricity supply industry. 2000. Available at SSRN 223648.

[31] Streimikiene D, Bruneckiene J, Cibinskiene A. The review of electricity market liberalization impacts on electricity prices. Transform. Bus. Econ. 2013;12:40-60.

[32] Swider DJ. Simultaneous bidding in day-ahead auctions for spot energy and power systems reserve. Int. J. Electr. Power Energy Syst. 2007;29(6):470-9.

[33] Tanrisever F, Derinkuyu K, Heeren M. Forecasting electricity infeed for distribution system networks: an analysis of the Dutch case. Energy 2013;58:247-57.

[34] Tennet. The imbalance pricing system as at 01-01-2001, revised per 26-102005. Tennet. 2010.

[35] Tennet. Preparation of E-programmes \& T-forecast. 2010. 〈http://www.Tennet. eu/nl/about-Tennet/news-press-publications/publications/technical-publica tions/preparation-e-programmes-and-t-forecasts.html $\rangle$.

[36] Tennet. Tennet primary reserves. 2013. 〈http://www.Tennet.org/english/opera tional_management/ system_data_preparation/primary_reserve.aspx $>$.

[37] Tennet. Transmission Capacity Outlook 2014. 2014. 〈http://www.Tennet.org/ controls/DownloadDocument.ashx?documentID $=11$.

[38] Tennet. Bid price ladder. 2014. 〈http://www.tennet.org/english/operational_ management/system_data_preparation/offering_regulating_reserve_capacity/ bid_price_ladder.aspx $>$.

[39] Tennet. Imbalance prices. 2014. 〈http://www.tennet.org/english/operational_ management/System_data_relating_processing/settlement_prices/index. aspx $>$.

[40] TSOs AE. Intraday cross border The Netherlands - Belgium. Amsterdam: APX ENDEX; 2010.

[41] Vandezande L, Meeus L, Belmans R, Saguan M, Glachant JM. Well-functioning balancing markets: a prerequisite for wind power integration. Energy Policy 2010;38(7):3146-54

[42] WEF. The global energy architecture performance index report 2015. 2015. 〈http://www3.weforum.org/docs/WEF_GlobalEnergyArchitecture_2015.pdf〉.

[43] Wenting F. Programmaverantwoordelijkheid. Arnhem: Tennet; 2002.

[44] Woo CK, Lloyd D, Tishler A. Electricity market reform failures: UK, Norway, Alberta and California. Energy policy 2003;31(11):1103-15. 